ORIGINAL ARTICLE

\title{
Potential role of interleukin 6 in reactive thrombocytosis and acute phase response in pulmonary tuberculosis
}

\author{
E Ünsal, S Aksaray, D Köksal, T Șipit
}

Postgrad Med J 2005;81:604-607. doi: 10.1136/pgmj.2004.030544

See end of article for authors' affiliations

Correspondence to: Dr D Köksal, Feneryolu sok. 5/21, 06010 Etlik, Ankara, Turkey; deniz_koksal@yahoo.com

Submitted

11 November 2004

Accepted 10 January 2005
Objective: Reactive thrombocytosis is found in a number of clinical situations including infectious diseases such as pulmonary tuberculosis (PTB). To examine the possible role of interleukin ( IL6) in reactive thrombocytosis and acute phase response in PTB this study measured serum IL6, C reactive protein (CRP), erythrocyte sedimentation rate (ESR), albumin concentrations in 62 PTB patients and 20 healthy volunteers. Method: PTB patients were divided into two groups based on thrombocyte counts. Twenty seven PTB patients with normal thrombocyte counts constituted group 1, 35 PTB patients with thrombocytosis constituted group 2 , and 20 healthy volunteers constituted group 3 .

Results: The median IL6 concentration of group 1 was $12.8 \mathrm{pg} / \mathrm{ml}(95 \% \mathrm{Cl}: 12.1$ to $56.9 \mathrm{pg} / \mathrm{ml})$ and group 2 was $40.6 \mathrm{pg} / \mathrm{ml}(95 \% \mathrm{Cl}: 67.1$ to $168.7 \mathrm{pg} / \mathrm{ml})$. The comparison of IL6 concentrations in the three groups was significant $(p=0.0001)$. Patients in group 1 had a higher concentration of CRP $(p=0.0001)$ and lower concentration of albumin $(p=0.002)$ than group 3 whereas group 2 had higher concentration of CRP ( $p=0.003)$ and lower concentration of albumin $(p=0.002)$ than group 1. Serum IL6 concentrations were significantly correlated with thrombocyte counts $(p=0.004, r=0.36), \operatorname{CRP}(p=0.007$, $r=0.34)$, and albumin concentrations $(p=0.005, r=-0.34)$. IL6 concentrations were significantly correlated with the number of involved zones $(p=0.005, r=0.35)$ and acid fast bacilli positivity $(p=0.03$, $r=0.27)$. Patients in group 2 had weight loss $(p=0.004)$, fever $(p=0.038)$, and night sweats $(p=0.007)$ more frequently than group 1. Also, group 2 had more extensive radiological findings (involved zones $p=0.001$, bilateral disease $p=0.0001$, presence of cavity $p=0.02$ ) than group 1 .

Conclusions: IL6 might play a contributory part in reactive thrombocytosis and acute phase response in PTB.
$\mathrm{R}$ eactive thrombocytosis is seen in a number of clinical situations including infectious diseases such as pulmonary tuberculosis (PTB)..$^{1-3}$ Several clinical and laboratory findings support the possible pathogenetic role of increased interleukin 6 (IL6) concentrations in reactive thrombocytosis as an acute phase response. ${ }^{145}$ IL6 is produced by a number of different cell types including $\mathrm{T}$ cells, B cells, monocytes, fibroblasts, and plays an important part in inflammation and immune response. ${ }^{67}$ It has been shown that IL6, a haematopoietic cytokine with multiple biological functions, has the capacity to induce megakaryocyte maturation in vitro and to increase the thrombocyte count in experimental animals. ${ }^{8}$ 9

In PTB IL6 might be synthesised and released after phagocytosis of Mycobacterium tuberculosis by macrophages followed by activation of inflammation cells and cause systemic effects such as the induction of acute phase reactants and thrombocytosis. ${ }^{10-13}$

The association between serum IL6 concentrations and reactive thrombocytosis in different clinical situations such as malignancy, autoimmune disorders, and surgery has been established in several studies. ${ }^{161415}$ There is only a limited number of studies investigating the thrombopoetic activity of IL6 in PTB. ${ }^{16}$ In this study, we aimed to investigate the possible role of IL6 in reactive thrombocytosis and acute phase response in PTB.

\section{METHODS \\ Patients}

Sixty two patients (52 male, 10 female) with newly diagnosed active PTB and 20 healthy volunteers as controls ( 13 male, 7 female) were enrolled in the study. The diagnosis of PTB was done based on a positive sputum smear for acid fast bacilli (AFB) and typical paranchymal tuberculosis on chest radiography. All patients were HIV negative and none of them had previously received antituberculosis chemotherapy. Patients with miliary tuberculosis, malignancy, autoimmune disorders, pregnancy, history of recent trauma or surgery, and treatment with immunosuppresive agents in the past six months were excluded from the study. In all of the subjects a detailed medical history was obtained and all of them underwent physical examination, chest radiography, and blood analysis including complete blood cell count, erythrocyte sedimentation rate (ESR), C reactive protein (CRP), albumin, and IL6. Sputum smear positivity for acid fast bacilli ranging between 1 to 4 positive $(1+, 2+, 3+, 4+)$ and radiological findings (unilateral, bilateral disease, presence of cavities, number of involved zones ranging between one to six zones) were recorded for each patient.

PTB patients were divided into two groups based on thrombocyte counts and a thrombocyte count higher than $400 \times 10^{9} / 1$ was considered as thrombocytosis. Twenty seven PTB patients with normal thrombocyte counts (mean (SD) $321(51) \times 10^{9} /$ l, range $\left.174-398 \times 10^{9} / 1\right)$ constituted group 1 and 35 PTB patients with thrombocytosis $\left(540(96) \times 10^{9} / 1\right.$, range $\left.417-826 \times 10^{9} / 1\right)$ constituted group 2 . Twenty healthy controls constituted group 3 . The study was approved by the local ethics committee of Atatürk Chest Diseases and Thoracic Surgery Education and Research Hospital and all subjects gave written informed consent.

\section{Study design}

Venous blood samples were collected starting antituberculosis chemotherapy and on the same day thrombocyte counts were analysed by automated complete blood cell counting device (Advia 120 Hematology System) on EDTA anticoagulated blood. The normal range for thrombocyte count was $150-400 \times 10^{9} / 1$. Serum albumin concentrations were

Abbreviations: PTB, pulmonary tuberculosis; CRP, $C$ reactive protein; ESR, erythrocyte sedimentation rate; IL6, interleukin 6 
Table 1 Comparison of mean ages, sex distribution, ESR, CRP, albumin, IL6 values, and thrombocyte counts of the study groups

\begin{tabular}{|c|c|c|c|c|c|}
\hline & $\begin{array}{l}\text { Group } 1 \\
(n=27)\end{array}$ & $\begin{array}{l}\text { Group 2 } \\
(n=35)\end{array}$ & $\begin{array}{l}\text { Group } 3 \\
(n=20)\end{array}$ & $\begin{array}{l}\text { Group 1-2 } \\
\text { p Value }\end{array}$ & $\begin{array}{l}\text { Group 1-3 } \\
\text { p Value }\end{array}$ \\
\hline Mean age (y) & $39(18$ & $36(13)$ & $35(10)$ & 0.7 & 0.8 \\
\hline Sex (male/female) & $19 / 8$ & $33 / 2$ & $13 / 7$ & $0.01^{*}$ & 0.6 \\
\hline $\operatorname{ESR}(\mathrm{mm} 1 \mathrm{st} h)$ & $61.6(26.2)$ & $68.9(21.6)$ & $12.9(5.8)$ & 0.1 & $0.0001^{*}$ \\
\hline CRP (mg/l) & $55.7(47.8)$ & $95.4(54.3)$ & $1.6(0.6)$ & $0.003^{*}$ & $0.0001^{*}$ \\
\hline Albumin (g/dl) & $3.7(0.6)$ & $3.2(0.5)$ & $4.2(0.5)$ & $0.002^{*}$ & $0.002^{\star}$ \\
\hline IL6 (pg/ml) & $34.5(58.4)$ & $117.9(150.4)$ & $<3.8$ & $0.0001^{*}$ & $0.0001^{*}$ \\
\hline Thrombocyte $\left(\times 10^{9} / 1\right)$ & $321(51)$ & $540(96)$ & $231(55)$ & $0.0001^{*}$ & $0.0001^{*}$ \\
\hline
\end{tabular}

Results expressed as mean (SD). Group 1: PTB patients with normal platelet count. Group 2: PTB patients with reactive thrombocytosis. Group 3: control group consisting healthy volunteers. ESR, erythrocyte sedimentation rate; CRP, C reactive protein; IL6, interleukin 6. *Significant.

measured by Beckman Coulter Synchron LX20 Oto Analyzer by BCP (Bromkresolpurpur) colorimetry method.

Serum samples were stored at $-40^{\circ} \mathrm{C}$ until the analysis of IL6 and CRP. Serum CRP concentrations were measured by nephelometry (Dade Behring, Germany). A level lower than $3.08 \mathrm{mg} / \mathrm{l}$ was considered to be normal. IL6 concentrations were measured by sandwich type enzyme immunoassay (Cytoimmune, USA). The limit of detection for IL6 was $3.8 \mathrm{pg} / \mathrm{ml}$ with a range of $8-500 \mathrm{pg} / \mathrm{ml}$. Lower values were considered undetectable.

\section{Statistical analysis}

Analysis of data was done using SPSS for Windows, release 10.0. The results were expressed as mean (SD). Groups were compared with the non-parametric Kruskal-Wallis test, Mann-Whitney $U$ test, and $\chi^{2}$ test. Correlation between the variables were examined by Spearman's rank correlation test. A p value less than 0.05 was considered significant.

\section{RESULTS}

Group 1 consisted of 27 patients ( 19 male, 8 female) with a mean (SD) age of 39 (18), group 2 consisted of 35 patients (33 male, 2 female) with a mean age of 36 (13), and group 3 consisted of 20 healthy volunteers ( 13 male, 7 female) with a mean age of 35 (10) years. Table 1 shows mean ages, sex distribution, ESR, CRP, albumin, IL6 values, and thrombocyte counts of the study groups.

When we compared PTB patients with normal thrombocyte counts (group 1) with healthy controls (group 3), group 1 had a higher level of IL6 $(p=0.0001)$, CRP $(p=0.0001)$, a lower concentration of albumin $(p=0.002)$, and a higher

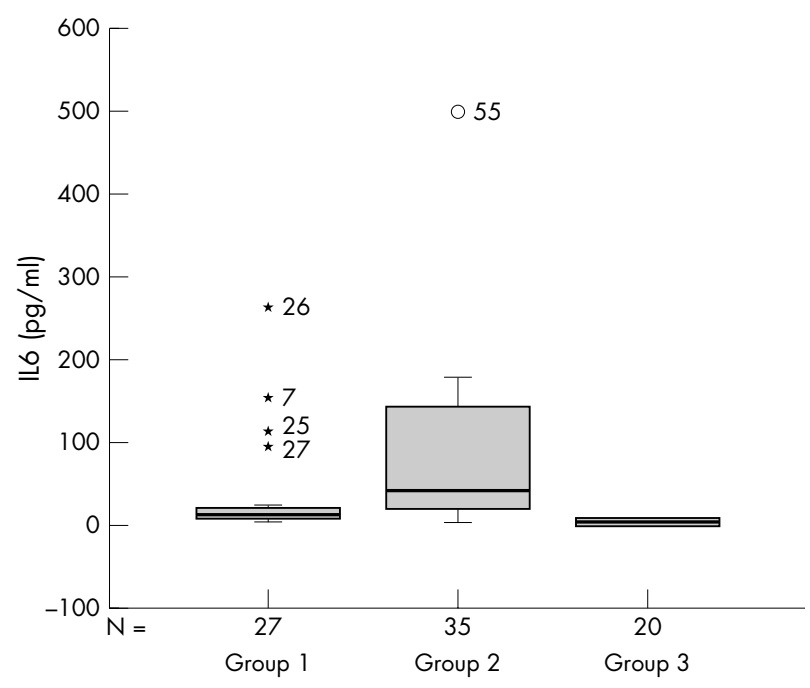

Figure 1 Median and interquartile range of IL6 concentrations of the study groups. thrombocyte count $(p=0.0001)$. When we compared PTB patients with normal thrombocyte counts (group 1) with PTB patients with thrombocytosis (group 2), group 2 had a higher concentration of IL6 $(p=0.0001)$, CRP $(p=0.003)$, a lower concentration of albumin $(p=0.002)$, and a higher thrombocyte count $(\mathrm{p}=0.0001)$.

The mean value of IL6 concentrations was 34.5 (58.4) (range: $<3.8-264 \mathrm{pg} / \mathrm{ml}$ ) in group 1 and 117.9 (150.4) (range: $<3.8-500 \mathrm{pg} / \mathrm{ml}$ ) in group 2 . Two patients in group 1 , one patient in group 2, and all the patients in group 3 had undetectable concentrations of IL6 $(<3.8 \mathrm{pg} / \mathrm{ml})$. Figure 1 shows the median and interquartile range of IL6 concentrations of the study groups. The median IL6 concentration of group 1 was $12.8 \mathrm{pg} / \mathrm{ml}$ (95\% CI: 12.1 to $56.9 \mathrm{pg} / \mathrm{ml}$ ) and group 2 was $40.6 \mathrm{pg} / \mathrm{ml}$ (95\% CI: 67.1 to $168.7 \mathrm{pg} / \mathrm{ml}$ ). The comparison of IL6 concentrations of the three groups was significant $(p=0.0001)$ (fig 1$)$.

Figure 2 shows the correlations between serum IL6 concentrations and ESR, CRP, albumin concentrations, and thrombocyte counts. Serum IL6 concentration was significantly correlated with thrombocyte counts $(\mathrm{p}=0.004$, $r=0.36)$, serum CRP concentrations $(\mathrm{p}=0.007, r=0.34)$, and albumin concentrations $(\mathrm{p}=0.005, r=-0.34)$. However, there was not a significant correlation between serum IL6 concentrations and ESR ( $\mathrm{p}=0.4, r=0.09)$.

The most common symptoms on admission were coughing $(90.3 \%)$, night sweats $(82.3 \%)$, sputum expectoration $(79 \%)$, weight loss (71\%), fever $(69.4 \%)$, dyspnea $(41.9 \%)$, chest pain $(35.5 \%)$, and haemoptysis $(32.3 \%)$. When the patients were grouped based on the presence of these symptoms, IL6 concentrations did not differ between the groups. However, patients in group 2 had the symptoms weight loss $(p=0.004)$, fever $(p=0.03)$, and night sweats $(p=0.007)$ more frequently than group 1 (table 2 ). Table 3 shows the comparisons of radiological findings and sputum smear positivity for AFB in group 1 and group 2. Patients in group 2 had more extensive radiological findings (involved zones $\mathrm{p}=0.001$, bilateral disease $\mathrm{p}=0.0001$, cavity present $\mathrm{p}=0.021$ ) than group 1 . AFB positivity did not differ between the groups $(p=0.7)$. Also, IL6 concentrations were significantly correlated with the number of involved zones $(\mathrm{p}=0.005, r=0.35)$ and AFB positivity $(\mathrm{p}=0.03, r=0.27)$.

\section{DISCUSSION}

In most of the infectious and inflammatory diseases, reactive thrombocytosis is seen frequently as a systemic inflammatory response. IL6 plays a pivotal part in this inflammatory response. IL6 induces acute phase proteins and in experimental studies it is known to increase thrombocyte counts. ${ }^{126}$ In our study we speculated that there might be a relation between thrombocytosis seen in PTB and serum IL6 concentration. We found serum IL6 concentrations higher in PTB patients with reactive thrombocytosis than the PTB patients with normal thrombocyte count. 

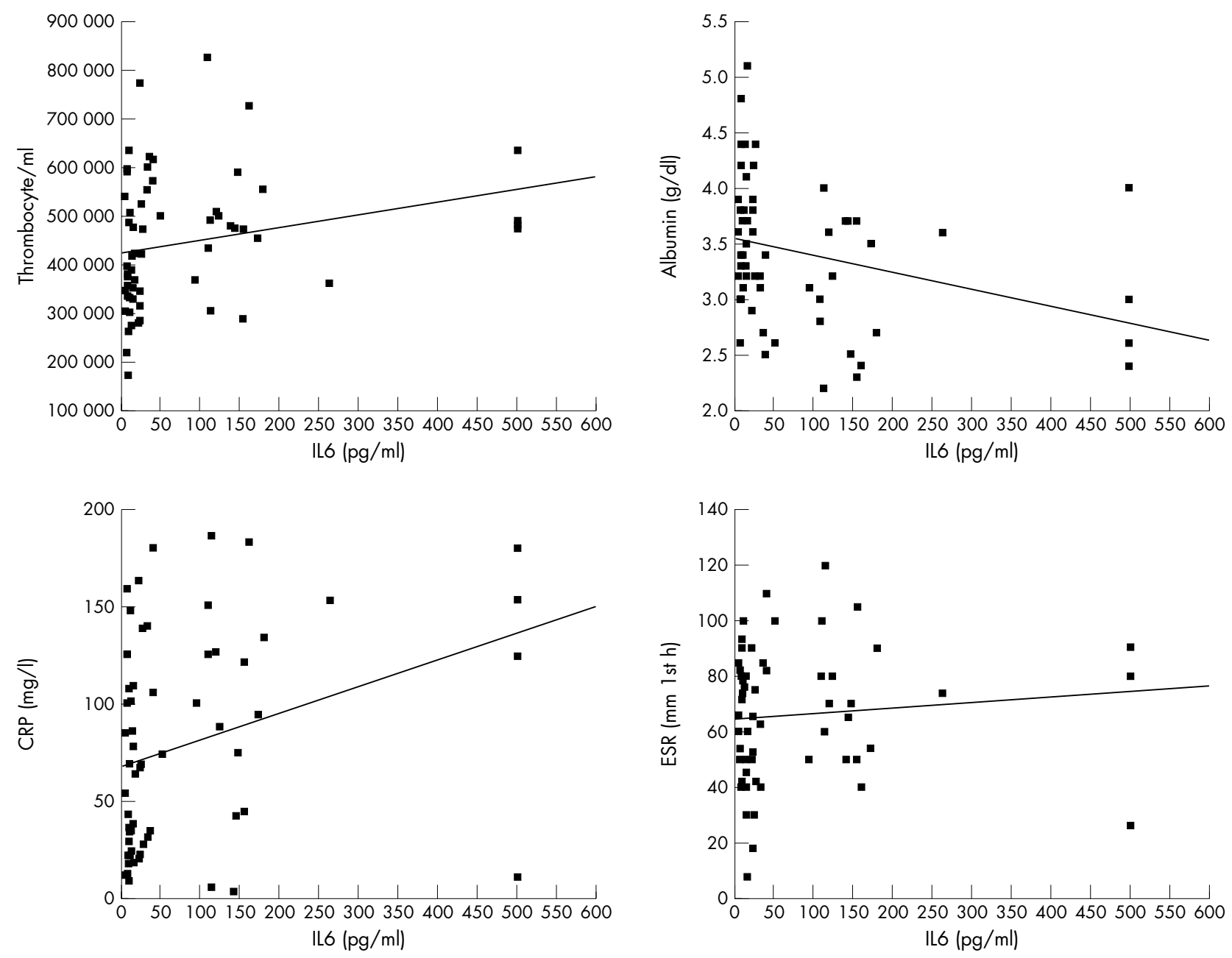

Figure 2 Correlation of serum IL6 concentration with the thrombocyte counts $(p=0.004, r=0.36)$, albumin concentrations $(p=0.005, r=-0.34)$, CRP concentrations $(p=0.007, r=0.34)$, and $\operatorname{ESR}(p=0.4, r=0.09)$.

IL6 has a potent thrombopoietic function and it has been shown to induce megakaryocytopoiesis in vitro and thrombocytosis in vivo. ${ }^{116}$ More direct evidence implicating IL6 as the possible cause of reactive thrombocytosis is the finding that rhesus monkeys treated with recombinant human IL6 had acute phase response and thrombocytosis. ${ }^{17}$ A number of studies have shown serum, plasma, pleural, and synovial fluid IL6 concentrations increased in patients with inflammatory disorders including rheumatoid arthritis and infectious diseases.461418 Yokoyama et al studied the thrombopoietic effect of IL6 produced in the pleural space. They reported pleural IL6 concentrations higher in patients with tuberculous pleurisy and significantly correlated with both platelet count and CRP values. ${ }^{16}$
IL6 synthesis may be induced by infectious agents and other cytokines such as interleukin l, tumour necrosis factor, and platelet derived growth factor. Reactive thrombocytosis is a cytokine driven process and IL6 may have a contributory role. ${ }^{146}$ However, in our study serum IL6 concentrations were found in low amounts to induce megakaryocytopoiesis. It is probable that detection of an increased IL6 concentration reflects recent IL6 release into circulation, as the half life of circulating IL6 is $>30$ minutes. ${ }^{4}$ Reactive thrombocytosis might be either mediated by high plasma concentrations of IL6 or associated with high plasma concentrations of IL6 in reaction to a common inflammatory process and the results of our study support the second idea.

\begin{tabular}{|llll|}
\hline \multicolumn{4}{l}{ Table 2 Comparison of admission symptoms between the patient groups } \\
\hline Symptoms & Group $\mathbf{1}(\mathbf{n}=\mathbf{2 7})$ & Group 2 ( $\mathbf{n = 3 5 )}$ & $\mathrm{p}$ Value \\
\hline Fever & $15(55.5)$ & $28(80)$ & $0.03^{*}$ \\
Night sweats & $18(66.6)$ & $33(94.2)$ & $0.007^{*}$ \\
Weight loss & $14(51.8)$ & $30(85.7)$ & $0.004^{*}$ \\
Coughing & $24(88.8)$ & $32(91.4)$ & 0.7 \\
Sputum expectoration & $21(77.7)$ & $28(80)$ & 0.8 \\
Dyspnea & $10(37)$ & $16(45.7)$ & 0.4 \\
Haemoptysis & $9(33.3)$ & $11(31.4)$ & 0.8 \\
Chest pain & $8(29.6)$ & $14(40)$ & 0.3 \\
\hline *Significant. Percentages shown in parentheses. & & \\
\hline
\end{tabular}


Table 3 Comparison of AFB positivity and radiological findings between the patient groups

\begin{tabular}{llll}
\hline & Group $1(\mathbf{n}=27)$ & Group $2(\mathbf{n}=\mathbf{3 5})$ & $\mathrm{p}$ Value \\
\hline AFB positivity (1-4 positivity) & $2.1(1.3)$ & $2.2(1.1)$ & 0.7 \\
Number of involved zones (1-6 zones) & $2.1(1.6)$ & $3.5(1.6)$ & $0.001^{*}$ \\
Presence of cavity & $9(33.3 \%)$ & $22(62.8 \%)$ & $0.02^{*}$ \\
Bilateral disease & $7(25.9 \%)$ & $25(71.4 \%)$ & $0.0001^{*}$ \\
\hline *Significant. Data mean (SD) unless shown otherwise. & & \\
\hline
\end{tabular}

Although a cause-effect relation remains unproved, inflammatory cytokines may play a part in augmenting platelet production in malignancy, chronic infectious diseases. In our study only two patients in group 1 and one patient in group 2 had an undetectable concentration of IL6 whereas other PTB patients had high concentrations of IL6. This suggests that PTB patients with reactive thrombocytosis frequently have increased IL6 concentrations, however the converse may not be true. As the platelet count is related not only to the rate of platelet production but also the rate of platelet destruction and loss.

Tuberculosis is an infectious disease characterised by cellular immune reaction. Mycobacterium tuberculosis and its components have been shown to stimulate mononuclear phagocytes in vitro to release IL6. ${ }^{10}{ }^{11}$ Activated macrophages accumulated in the tuberculous foci can synthesise and release various cytokines including IL6, which are regarded as inflammatory mediators. When they reach the systemic circulation, they cause systemic symptoms such as fever, malaise, and weight loss. ${ }^{12} 131920$

We found serum IL6 concentrations correlated with AFB positivity and radiological findings. Also PTB patients with reactive thrombocytosis had more extensive radiological findings and symptoms as fever, night sweats, weight loss than PTB patients with normal thrombocyte count. Our results support that there is a great inflammmatory response in PTB patients with reactive thrombocytosis and IL6 in plasma might serve as a marker to evaluate the disease activity in terms of cellular immune reaction.

Robson et al defined severe PTB characterised immunologically by an acute phase response. ${ }^{21}$ The acute phase response is the systemic inflammatory reaction for an infection or injury and acute phase proteins such as CRP and $\alpha_{1}$ antitrypsin are increased, whereas total protein and albumin concentrations are lowered. Evans et al reported in their study increased plasma concentrations of IL6 in patients with tuberculous osteomyelitis and significant correlation between serum IL6 concentrations and CRP, ESR, albumin values, all acute phase reactants. ${ }^{22}$

IL6 is known to induce hepatic acute phase reactants. ${ }^{167}$ CRP is an acute phase reactant whose hepatic synthesis may be mediated by IL6. ${ }^{23}$ Several clinical and laboratory findings support the significant relation between IL6 and CRP. ${ }^{120} 21$ CRP concentrations are increased in patients with high concentrations of IL6 and both values are reduced when antibody to IL6 is given to patients. ${ }^{24}$ In our study, serum IL6 concentrations showed significant correlations with thrombocyte counts, CRP, and albumin concentrations while no correlation was found between serum IL6 concentrations and ESR. Thus, our results support the theory that IL6 induces hepatic acute phase proteins in inflammatory diseases.

In conclusion, in PTB thrombocyte count and concentrations of acute phase reactants increase and IL6 might play a contributory part in this reactive thrombocytosis and acute phase response.

\section{Authors' affiliations}

E Ünsal, D Köksal, T Șipit, Chest Diseases and Tuberculosis Department, Atatürk Chest Diseases and Chest Surgery Education and Research Hospital, Turkey
S Aksaray, Microbiology Department, Ankara Numune Education and Research Hospital, Ankara, Turkey

Funding: none.

Conflicts of interest: none.

\section{REFERENCES}

1 Tefferi A, Ho TC, Ahmann GJ, et al. Plasma interleukin 6 and $C$ reactive protein levels in reactive versus clonal thrombocytosis. Am J Med 1994;97:374-8.

2 Turken $\mathrm{O}$, Kunter $\mathrm{E}$, Sezer $M$, et al. Hemostatic changes in active pulmonary tuberculosis. Int J Tuberc Lung Dis 2002;6:927-32.

3 Baynes RD, Boyhwell TH, Flax H, et al. Reactive thrombocytosis in pulmonary tuberculosis. J Clin Pathol 1987;40:676-9.

4 Hollen CW, Henthorn J, Koziol JA, et al. Elevated serum interleukin 6 levels in patients with reactive thrombocytosis. $\mathrm{Br} J$ Haematol $1991 ; 79: 286-90$.

5 Kaser A, Brandacher G, Steurer W, et al. Interleukin 6 stimulates thrombopoiesis through thrombopoietin: role in inflammatory thrombocytosis. Blood 2001;98:2720-5.

6 Baver J, Herrmann F. Interleukin 6 in clinical medicine. Ann Hematol $1991 ; 62: 203-10$.

7 Kishimoto T. The biology of interleukin 6. Blood 1989;74:1-10.

8 Kimura H, Ishibashi T, Uchida T, et al. Interleukin 6 is a differentiation factor for human megakaryocytes in vitro. Eur $\mathrm{J}$ Immunol 1990;20:1927-31.

9 Hill RJ, Warren MK, Levin J. Stimulation of thrombopoiesis in mice by human recombinant interleukin 6. J Clin Invest 1990;85:1242-7.

10 Poveda F, Camacho J, Arnalich F, et al. Circulating cytokine concentrations in tuberculosis and other chronic bacterial infections. Infection 1999;27:272-4.

11 Orme IM, Andersen P, Boom WH. T cell response to Mycobacterium tuberculosis. J Infect Dis 1993;167:1481-97.

12 Law K, Weiden M, Harkin T, et al. Increased release of interleukin 1 beta, interleukin 6 and tumor necrosis factor alpha by bronchoalveolar cells lavaged from involved sites in pulmonary tuberculosis. Am J Respir Crit Care Med 1996;153:799-804.

13 Ogawa T, Uchida $\mathrm{H}$, Kusumoto $\mathrm{Y}$, et al. Increase in tumor necrosis factor alpha and interleukin 6 secreting cells in peripheral blood mononuclear cells from subjects infected with Mycobacterium tuberculosis. Infect Immun $1991 ; 59: 3021-5$.

14 Haznedaroğlu IC, Ertenli I, Özcebe OI, et al. Megakaryocyte related interleukins in reactive thrombocytosis versus autonomous thrombocythemia. Acta Haematol 1996;95:107-11

15 Nakano T, Chahinian AP, Shinjo M, et al. Interleukin 6 and its relationship to clinical parameters in patients with malignant pleural mesothelioma. Br J Cancer 1998;77:907-12.

16 Yokoyama A, Maruyama $M$, Ito $M$, et al. Interleukin 6 activity in pleural effusion. Its diagnostic value and thrombopoietic activity. Chest 1992; 102:1055-9.

17 Mayer P, Geissler K, Valent P, et al. Recombinant human interleukin 6 is a potent inducer of the acute phase response and elevates the blood platelets in nonhuman primates. Exp Hematol 1991;19:688-96

18 Hoheisel G, Izbicki G, Roth M, et al. Compartmentalization of proinflammatory cytokines in tuberculous pleurisy. Respir Med 1998;92:14-17.

19 Tsao TC, Hong J, Huang C, et al. Increased TNF alpha, IL 1 beta and IL 6 levels in the bronchoalveolar lavage fluid with the upregulation of their mRNA in macrophages lavaged from patients with active pulmonary tuberculosis. Tuber Lung Dis 1999:79:279-5

20 El-Ahmady O, Mansour M, Zoeir $\mathrm{H}$, et al. Elevated concentrations of interleukins and leukotriene in response to Mycobacterium tuberculosis infection. Ann Clin Biochem 1997;34:160-4.

21 Robson SC, White NW, Aronson I, et al. Acute phase response and the hypercoagulable state in pulmonary tuberculosis. Br J Haematol 1996;93:943-9.

22 Evans CA, Jellis J, Hughes SP, et al. Tumor necrosis factor alpha, interleukin 6 and interleukin 8 secretion and the acute phase response in patients with bacterial and tuberculous osteomyelitis. J Infect Dis 1998; 177:1582-7.

23 Nijsten MWN, de Grott ER, ten Duis HJ, et al. Serum levels of interleukin 6 and acute phase responses. Lancet 1987; ;ii:921.

24 Klein B, Wijdenes J, Zhang XG, et al. Murine anti-interleukin 6 monoclonal antibody therapy for a patient with plasma cell leukemia. Blood 1991;78:1198-204. 